\title{
Case report: AID, a new principle of correction to treat proximal structural curve with a brace
}

\author{
Manuel Rigo \\ From 11th International Conference on Conservative Management of Spinal Deformities - SOSORT 2014 \\ Annual Meeting \\ Wiesbaden, Germany. 8-10 May 2014
}

\section{Background}

There is no wide accepted principle to brace primary thoracic double major and triple structural curve patterns. Axial elongation from a super-structure or three-point system with a neck semi-ring are some of the previously proposed principles.

\section{Aim}

The purpose of this case report is to present a new principle of correction based on axial compression on the convex ribs of the proximal curve.

\section{Case report}

A 14 year old was diagnosed with AIS at 10 years of age. In a first X-ray from February 2010 it was noted a right thoracic curve measuring $7^{\circ} \mathrm{Cobb}$, combined with a left lumbar measuring $7^{\circ} \mathrm{Cobb}$. Proximal thoracic region was not measurable. One year later, February 2011 the Cobb angles progressed to $18^{\circ}$ and $13^{\circ}$ respectively, and progression was confirmed on September 2011 with a Cobb angle of $24^{\circ}$ in the main thoracic and $26^{\circ}$ in the lumbar curve. She was treated with a Boston brace showing poor inbrace correction, with $17^{\circ}$ lumbar, $22^{\circ}$ main thoracic and $19^{\circ}$ proximal curves. In a new X-ray out of brace on May 2012 the angles were $19^{\circ}, 18^{\circ}$ and $21^{\circ}$. With her second Boston brace the values were $19^{\circ}, 18^{\circ}$ and $25^{\circ}$ respectively. On December 2012 and with no new reference out-brace the brace was changed to a classical Chêneau type brace, with no in-brace X-ray, mainly due to the over-exposition. Menarche on April 2013. New X-ray on June showed a progression to $21^{\circ}, 25^{\circ}$ and $31^{\circ}$ respectively. Due to the bad evolution of the proximal curve we designed a removable superstructure with a combined mechanism: compression on the convex proximal curve and three-point

Institut Elena Salva, Barcelona, Spain 